\section{Cheiloscopic Study among Monozygotic Twins, Non-Twin Brothers and Non-Relative Individuals}

Larissa Chaves Cardoso Fernandes ${ }^{1}$, Julyana de Araújo Oliveira ${ }^{2}$, Bianca Marques Santiago², Patrícia Moreira Rabello², Marcus Vitor Diniz de Carvalho ${ }^{1}$, Reginaldo Inojosa Carneiro Campello ${ }^{1}$, Evelyne Pessoa Soriano ${ }^{1}$
'UPE - Universidade de

Pernambuco, Recife, PE, Brazil ${ }^{2}$ Department of Clinical and Social Dentistry, UFPB - Universidade Federal da Paraíba, João Pessoa, PB, Brazil

Correspondence: Evelyne Pessoa Soriano, Estrada de Aldeia Km 13 Cond. Torquato Castro 1 Casa 200, Aldeia, 54783-010 Camaragibe, PE, Brasil. Tel: +55-81-3266-5926. e-mail: evelyne.soriano@upe.br

This study aimed to investigate cheiloscopic patterns among monozygotic twins (MT), non-twin siblings (NTS) and unrelated individuals (UI). The sample consisted of 20 pairs of monozygotic twins (G1), 20 pairs of non-twin siblings (G2) and 20 pairs of unrelated individuals (G3). Lip thickness, commissures and grooves were evaluated and the latter were classified as: I - clear-cut vertical grooves; I' - incomplete vertical grooves; II - branched grooves; III - intersecting; IV - reticular grooves and V - undetermined, in 8 labial regions (sub-quadrants). The data were analyzed using descriptive and inferential statistics, with a 5\% significance level. Concordance Correlation Coefficient (CCC) and Kappa coefficient, with a $95 \%$ confidence interval, were employed to check for agreement rates between $\mathrm{G} 1, \mathrm{G} 2$ and $\mathrm{G} 3$ pairs. There was a weak correlation for lip thickness $(<0.90)$ in the total group, with higher values in $\mathrm{G} 1$ (CCC from 0.25 to 0.83 and from 0.34 to 0.86 , upper and lower lips, respectively), followed by G2 (CCC from -0.03 to 0.70 and from -0.21 to 0.62 , upper and lower lips, respectively) and G3 (CCC from -0.25 to 0.56 and from -0.38 to 0.34 , upper and lower lips, respectively). With regard to labial commissures, Kappa statistic values were found to be 1.00 for $\mathrm{G} 1,0.45$ for $\mathrm{G} 2$ and -0.24 for $\mathrm{G} 3$. As for the main groove pattern by sub-quadrant, Kappa values ranged from 0.48 to 0.87 for $\mathrm{G} 1$, from 0.17 to 0.59 for $\mathrm{G} 2$, and from -0.18 to 0.19 for $\mathrm{G} 3$. Monozygotic twins presented a relevant percentage of cheiloscopic agreements. Similarities were also found among NTS, while UI showed greater differences compared to their pairs, highlighting the influence of hereditary relationships on inherited cheiloscopic features.

Key Words: forensic sciences, forensic anthropology, forensic dentistry, lip, twins, monozygotic.

\section{Introduction}

Cheiloscopy is referred to as the registration and classification of the human lip transition zone, which is located between the inner mucosa and the lip skin. Its scientific basis lies on the fact that this area contains small grooves that denote individual differences in response to a genetic background and are considered unique to humans $(1,2)$. In addition to grooves, cheiloscopy also holds the study of other variables, like lip thickness and the pattern of lip commissures, which could be criteria for acceptance or decline of a suspicious record, previous to thorough observation of the grooves in a comparative investigation (3).

Although cheiloscopy has not been a routine technique used in human identification, it can be useful for criminal investigations as it allows the comparison of lip prints left on objects or belongings (4-6).

Lip prints are different from each other and between different individuals, providing them with characteristics of specificity found in the method (7). With regard to the issue of immutability, it is worth noting that after an infection, particularly a herpetic one, the original shape of the lips and of their grooves returns as the injuries heal (8).
Monozygotic twins constitute a peculiarity inherent to cheiloscopy. Studies of lip prints on monozygotic twins have shown that prints are quite similar but not equal and that relatives may have some degree of similarity concerning the predominant groove patterns, since lip prints seem to undergo strong influence by heredity $(9,10)$. However, these studies did not indicate the percentage of agreements and divergences between the pairs of a family sample (twin and non-twin siblings), an important fact in determining the cheiloscopic uniqueness of each human individual.

Thus, this study aimed to investigate comparatively the aspects inherent to the uniqueness of cheiloscopy by means of percent agreement in three groups: monozygotic twins, non-twin siblings of same parentage and unrelated individuals.

\section{Material and Methods}

This was a blind, cross-sectional, quantitative study with inductive approach and extensive direct observation carried out in the city of João Pessoa, PB, Brazil. The sample consisted of 3 groups of 20 pairs of monozygotic twins (Group $1=\mathrm{G} 1$ ), 20 pairs of non-twin siblings of same parentage (Group $2=\mathrm{G} 2$ ), and 20 pairs of individuals 
without common genetic heritage (Group $3=\mathrm{G} 3$ ). Subjects aged between 15 and 27 years were chosen and paired by age and sex, in order to nullify confounding variables. With regard to the group of non-twin siblings and unrelated individuals, an age difference of up to 3 years between pairs was accepted. Twins were selected using a random decision system and all available twin pairs were included, while the other groups were chosen by paired randomization (11). Individuals presenting inflammation, trauma, malformation or other conditions affecting their oral and perioral regions were excluded from this study.

This research has followed strict ethical standards, respecting the individual rights of each participant, with prior approval (Protocol \#0289/11) of the Research Ethics Committee at the Center for Health Sciences. An informed consent was obtained from all participants included in the study. The objectives and benefits of the research were explained to the volunteers, in addition to standard ethical criteria on research involving human subjects. Family members who did not agree with the participation of their children in the study had their decision respected without being subjected to any harm or embarrassment. Moreover, even with the permission of the guardians, minors had their will respected, proceeding in accordance with their agreement.

Data collection was based on three steps: measurement of lip thickness, classification of the lip commissures and assessment of the groove pattern (3). A previous pilot study $(n=10)$, was carried out to calibrate the examiner. The data were statistically analyzed using the intra-class correlation coefficient for numerical variables and Kappa statistics for categorical variables, which indicated satisfactory values ranging from 0.922 to 0.984 and from 0.767 to 1 , respectively.

Before starting the data collection, the lips were cleaned using a paper napkin and after the examiner made sure that lips were free of cosmetics and other impurities, they used a compass tool and a millimeter ruler to measure the upper and lower lip thickness individually at the level of the midline. The lips were classified as (12): thin (under $8 \mathrm{~mm}$ ), medium (08-10 mm), thick or very thick (over 10 $\mathrm{mm}$ ) and mixed (when the upper and lower lips were not classified in the same category).

For the analysis of the arrangement of the lip commissures, photographs in automatic mode were taken with a high-resolution digital camera (Sony ${ }^{\circledR}$ CyberShot DSC H50, 16 Megapixels, Brazil) without flash. Participants were positioned to have the Frankfurt plan parallel to the ground and lips at rest. The arrangement of the lip commissures was classified in three types according to their position in relation to a line tangent to the labial tubercle and perpendicular to the midline, as follows (3): horizontal (commissures on the tangent line), high (commissures above the tangent line) and low (commissures below the tangent line).

To obtain the lip prints, individual samples containing $0.8 \mathrm{~g}$ of lipstick (Avon ultra-color rich, intense color lipstick ${ }^{\circledR}$, São Paulo, SP, Brazil, Real Red color, long-term) were used for each participant. Then the lips were pressed in a left-to-right scroll movement against a white cardboard placed on a glass plate. The printing was protected with transparent 48-mm-wide adhesive tape (Reference 5803 Scotch $3 \mathrm{M}^{\circledR}$, São Paulo, SP, Brazil).

Next, the lip prints were divided into 4 quadrants and 8 sub-quadrants and the frequency of the predominant types of groove determined the following classification (8): Type I (clear-cut vertical grooves); Type l' (incomplete vertical grooves); Type II (branched or bifurcate grooves); Type III (intersecting or "X" grooves); Type IV (reticulated grooves); Type $V$ (grooves with other forms that did not fit in any of the previous parameters) (Fig. 1).

The quantitative data obtained in this study were managed and treated by the Statistical Package for the Social Sciences (SPSS ${ }^{\circledR}$ ), version 20.0 and using descriptive and inferential statistics. Pearson's chi-square test was used to check for association between two categorical variables, with a $5.0 \%$ significance level. The Concordance Correlation Coefficient (CCC) (for numerical variables) and Kappa coefficient (for categorical variables) were employed to check agreement rates among the pairs of monozygotic twins, non-twin siblings and unrelated individuals, with a 95\% confidence interval. Based on the results, the distribution of absolute and/or percentage frequency was carried out for all variables, which were presented in tables for sample characterization and data description.

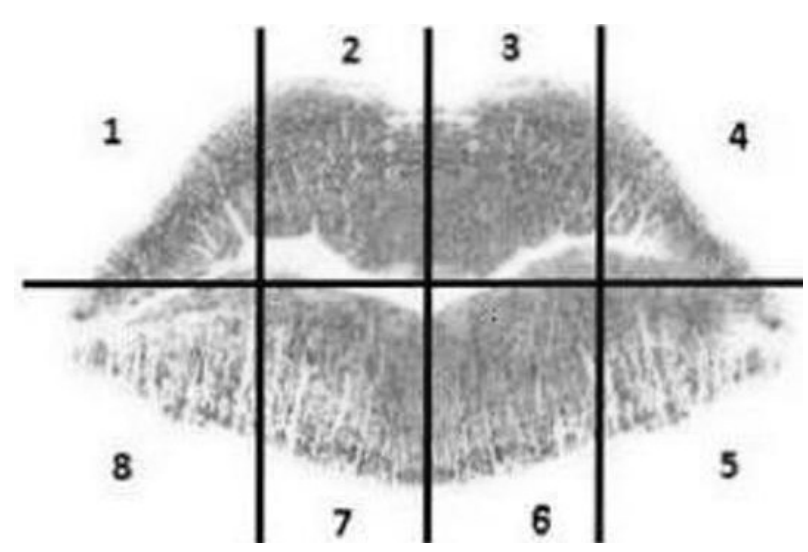

Figure 1. Schematic division of the lips into eight sub-quadrants, as follows: 1 and 2: upper right subquadrants; 3 and 4: upper left subquadrants; 5 and 6: lower left sub-quadrants; and 7 and 8: lower right sub-quadrants. 


\section{Results}

In the total sample, $65.0 \%$ of the pairs were female. The mean age ( \pm standard deviation) of individuals in $\mathrm{G} 1$, $\mathrm{G} 2$ and $\mathrm{G} 3$ was $21.10 \pm 2.95$ years, $21.40 \pm 2.55$ years and $21.25 \pm 2.99$ years, respectively.

With regard to the lip thickness, thick lips were prevalent in both G1 (47.5\%) and G2 (42.5\%); there was a higher prevalence of mixed lips in G3 (47.5\%), where the upper lip was classified mostly as medium (37.5\%) and the lower lip as thick or very thick (47.5\%). Table 1 shows the agreement rates between the maximum thickness of the upper and lower lips and their respective confidence intervals. According to McBride (13), there was a weak correlation $(<0.90)$ for the total group, with higher values in monozygotic twins (from 0.25 to 0.83 and from 0.34 to 0.86 , upper and lower lips, respectively), followed by non-twin siblings (from -0.03 to 0.70 and from -0.21 to 0.62 , upper and lower lips, respectively) and unrelated individuals (from -0.25 to 0.56 and from -0.38 to 0.34 , upper and lower lips, respectively).

As for the variable lip commissures, the horizontal

Table 1. Concordance correlation coefficient (CCC) for each variables in the analysis of monozygotic twins (G1), non-twin siblings (G2) and unrelated individuals (G3)

\begin{tabular}{llcc}
\hline \multirow{2}{*}{ Group } & Variable & \multicolumn{2}{c}{ CCC } \\
\cline { 3 - 4 } & Value & 95\% CI \\
\hline G1 & $\begin{array}{c}\text { Maximum thickness } \\
\text { of upper lips } \\
\text { Maximum thickness } \\
\text { of lower lips } \\
\text { Maximum thickness } \\
\text { of upper lips }\end{array}$ & 0.61 & 0.25 to 0.83 \\
G2 & 0.40 & -0.03 to 0.70 \\
& $\begin{array}{c}\text { Maximum thickness } \\
\text { of lower lips } \\
\text { Maximum thickness } \\
\text { of upper lips }\end{array}$ & 0.25 & -0.21 to 0.62 \\
G3 & 0.19 & -0.25 to 0.56 \\
\hline $\begin{array}{c}\text { Maximum thickness } \\
\text { of lower lips }\end{array}$ & -0.03 & -0.38 to 0.34 \\
\hline
\end{tabular}

pattern predominated among the analyzed groups ( $\mathrm{G} 1$ and $\mathrm{G} 3=65.0 \% ; \mathrm{G} 2=70.0 \%$ ), followed by the low type (commissures below the tangent line) ( $\mathrm{G} 1=25.0 \% ; \mathrm{G} 2=$ $22.5 \%$ and $\mathrm{G} 3=17.5 \%)$ and the high type $(\mathrm{G} 1=10.0 \%$; $\mathrm{G} 2=7.5 \%$ and $\mathrm{G} 3=17.5 \%$ ).

Lip grooves type I' (40.0\%) and I (52.5\%) were the most prevalent in $\mathrm{G} 1$ in the upper and lower sub-quadrants, respectively. In $\mathrm{G} 2$, type I grooves prevailed in both the upper (32.5\%) and lower (52.5\%) sub-quadrants. As for G3, types I and I' prevailed in the upper (27.5\%) and lower $(45.0 \%)$ sub-quadrants, respectively.

The agreement values for categorical variables concerning monozygotic twins, non-twin siblings and unrelated individuals are presented in Tables 2 to 4 . Table 2 shows the variation in agreement percentages among $\mathrm{G} 1$ (60.0\% to $100.0 \%)$, G2 (65.0\% to $75.0 \%)$ and G3 (30.0\% to $45.0 \%$ ). A Kappa value (14) of 1.0 was obtained in the group with monozygotic twins for lip commissures, while values ranging from 0.24 to 0.43 (fair agreement) were obtained for the other variables (lip thickness, upper and lower, mixed). As for non-twin siblings, Kappa values ranged from 0.29 (fair agreement) to 0.45 (moderate agreement), whereas in the group with unrelated individuals the values ranged from -0.24 to 0.04 (poor agreement).

\section{Discussion}

In addition to lip grooves, other phenotypic features of the lips, although not exclusive, may be used during the cheiloscopic identification, like for instance, thickness and commissure pattern (3). In this study, both the lip thickness and the commissure pattern showed a considerable agreement for the groups of twin and non-twin siblings, diverging from those of unrelated individuals. However, the use of lip thickness and commissures as acceptance or decline variables for further analysis of lip prints may turn to be unviable for the identification of twin and non-twin biological siblings. In these cases, a direct analysis of the lip grooves seems to be more appropriate. The reason for this approach can be evidenced by finding that all pairs of

Table 2. Analysis of agreement between G1, G2 and G3 pairs for the variables lip thickness, upper and lower mixed lips, and commissures

\begin{tabular}{|c|c|c|c|c|c|c|}
\hline \multirow{3}{*}{ Variable } & \multicolumn{6}{|c|}{ Groups } \\
\hline & \multicolumn{2}{|r|}{ G1 } & \multicolumn{2}{|r|}{ G2 } & \multicolumn{2}{|r|}{ G3 } \\
\hline & $\% 0^{(1)}$ & K $(95 \%$ CI $)$ & $\%$ & K $(95 \%$ CI $)$ & $\%$ & K (95\% CI) \\
\hline Lip thickness & 65.0 & 0.43 (0.09 to 0.77$)$ & 65.0 & 0.43 (0.12 to 0.75$)$ & 30.0 & $-0.05(-0.31$ to 0.20$)$ \\
\hline Upper mixed lips & 60.0 & $0.25(-0.14$ to 0.63$)$ & 65.0 & $0.29(-0.14$ to 0.71$)$ & 40.0 & $0.04(-0.24$ to 0.31$)$ \\
\hline Lower mixed lips & 60.0 & $0.24(-0.14$ to 0.62$)$ & 65.0 & $0.29(-0.14$ to 0.71$)$ & 45.0 & $-0.04(-0.43$ to 0.35$)$ \\
\hline Lip commissure & 100.0 & 1.00 (1.00 to 1.00$)$ & 75.0 & 0.45 (0.08 to 0.83$)$ & 35.0 & $-0.24(-0.22$ to 0.17$)$ \\
\hline
\end{tabular}

(1) Agreement percentage based on the analysis of 20 pairs. 
monozygotic twins (G1) concurred with the commissure pattern. According to Shandu et al. (15), the lip prints are considered unique to each individual and can be used as a method of identification in forensic dentistry based on the positioning and shape of grooves found in the human lips. Prabhu et al. (16) points out that the marks left by the lip vermilion are useful for forensic investigations, since it is not hard to find these marks at a crime scene. This fact leads the lip grooves to play a key role in cheiloscopic identification $(17,18)$. Nevertheless, as a relevant percentage of agreement for the predominance of a given groove pattern by region was found in this study, one should thoroughly examine selective points originated from secondary/less expressive grooves in each sub-quadrant, which would be analogous to the observation of dactyloscopy remarks.

In this study, analysis of the percentage of agreement between the pairs as to the predominant groove pattern, revealed a greater number of agreements in $\mathrm{G} 1$ for all subquadrants. A 90.0\% agreement was found in this group for the sub-quadrants 1 and 7 . In order to investigate the hereditary influence of inherited lip patterns, Tsuchihashi (8) carried out a study with 1,364 individuals, including

Table 3. Analysis of agreement between G1, G2 and G3 for the variable main lip groove type per sub-quadrant

\begin{tabular}{|c|c|c|c|c|c|c|}
\hline \multirow{3}{*}{ Sub-quadrant } & \multicolumn{6}{|c|}{ Groups } \\
\hline & \multicolumn{2}{|r|}{ G1 } & \multicolumn{2}{|r|}{ G2 } & \multicolumn{2}{|r|}{ G3 } \\
\hline & $\% 0^{(1)}$ & K $(95 \%$ CI) & $\%$ & $\mathrm{~K}(95 \% \mathrm{CI})$ & $\%$ & $\mathrm{~K}(95 \% \mathrm{CI})$ \\
\hline Sub-quadrant 1 & 90.0 & 0.87 (0.70 to 1.00 ) & 40.0 & $0.23(-0.05$ to 0.49$)$ & 25.0 & $0.06(-0.12$ to 0.24$)$ \\
\hline Sub-quadrant 2 & 75.0 & 0.67 (0.44 to 0.90$)$ & 65.0 & $0.54(0.29$ to 0.80$)$ & 5.0 & $-0.18(-0.29$ to -0.06$)$ \\
\hline Sub-quadrant 3 & 80.0 & 0.74 (0.52 to 0.96$)$ & 70.0 & 0.59 (0.32 to 0.85$)$ & 20.0 & $0.02(-0.17$ to 0.22$)$ \\
\hline Sub-quadrant 4 & 60.0 & 0.48 (0.19 to 0.77$)$ & 35.0 & $0.18(-0.08$ to 0.44$)$ & 35.0 & $0.16(-0.08$ to 0.36$)$ \\
\hline Sub-quadrant 5 & 80.0 & 0.68 (0.40 to 0.96$)$ & 50.0 & $0.17(-0.12$ to 0.46$)$ & 40.0 & $0.06(-0.23$ to 0.35$)$ \\
\hline Sub-quadrant 6 & 85.0 & $0.71(0.45$ to 0.97$)$ & 55.0 & 0.32 (0.03 to 0.61$)$ & 35.0 & $0.07(-0.23$ to 0.37$)$ \\
\hline Sub-quadrant 7 & 90.0 & 0.80 (0.56 to 1.00$)$ & 50.0 & $0.17(-0.18$ to 0.51$)$ & 45.0 & $0.19(-0.08$ to 0.46$)$ \\
\hline Sub-quadrant 8 & 80.0 & 0.73 (0.50 to 0.96$)$ & 60.0 & $0.23(-0.12$ to 0.58$)$ & 40.0 & $0.08(-0.24$ to 0.40$)$ \\
\hline
\end{tabular}

(1) Agreement percentage based on the analysis of 20 pairs.

Table 4. Analysis of agreement among twins for the upper and lower lip groove type (total)

\begin{tabular}{|c|c|c|c|c|c|c|}
\hline \multirow{3}{*}{ Lip groove type } & \multicolumn{6}{|c|}{ Groups } \\
\hline & \multicolumn{2}{|r|}{ G1 } & \multicolumn{2}{|r|}{ G2 } & \multicolumn{2}{|r|}{ G3 } \\
\hline & $\%(1)$ & $\mathrm{K}(95 \% \mathrm{CI})$ & $\%$ & $\mathrm{~K}(95 \% \mathrm{CI})$ & $\%$ & $\mathrm{~K}(95 \% \mathrm{CI})$ \\
\hline Upper lip groove - total & 80.0 & 0.72 (0.49 to 0.95$)$ & 65.0 & 0.60 (0.34 to 0.86$)$ & 20.0 & $-0.01(-0.21$ to 0.18$)$ \\
\hline Lower lip groove - total & 80.0 & $0.70(0.45$ to 0.95$)$ & 55.0 & $0.27(-0.07$ to 0.60$)$ & 45.0 & $0.18(-0.09$ to 0.45$)$ \\
\hline
\end{tabular}

(1) Agreement percentage based on the analysis of 20 pairs. 
obtained in the groups $\mathrm{G} 1$ and $\mathrm{G} 3$, also emphasizes the importance of hereditary determinants for cheiloscopic features, as reported in the literature.

According to some authors $(8,19-21)$, children may have predominant lip groove patterns compared to each other, possibly inherited from one of their parents, which highlights the influence of a hereditary background on the cheiloscopic identity. Such inferences corroborate the aforementioned study, as G2 (composed of nontwin siblings of same parentage) had relevant values of agreement between the pairs in some sub-quadrants. It was observed that in the more medial regions of the upper lip, G2 showed a $65.0 \%$ agreement for the sub-quadrant 2 and $70.0 \%$ for the sub-quadrant 3, with values similar to those observed for $\mathrm{G} 1$ (75.0\% and $80.0 \%$, respectively). In six out of the eight sub-quadrants, G2 had a value greater than or equal to $50.0 \%$ as regards the same main groove pattern found during pairing. As the lip grooves tend to respond to a hereditary basis, there was higher percentage of non-agreements among the subjects of G3, which showed Kappa agreement values lower than those of monozygotic twins.

Thus, this study was based on a quantitative analysis in which the variable was consistently categorized with the predominant groove pattern. Despite the limitation of not considering more remote secondary grooves, which are important to enable the uniqueness of the technique in the specific case of monozygotic twins or even non-twin siblings, few studies correlated a numerical value to the agreements and non-agreements found among family members. It should be emphasized that the methods used in this study indicated the most prevalent groove type in each lip sub-quadrant, in order to determine whether they follow a pattern influenced by heredity. Despite the matching patterns obtained between twins and non-twins, the methodology employed in criminal cases seeks the frequency of characteristic coincident points between the lip prints generated by the suspect and those found on investigated surfaces. These overlapping points are not determined only by the standard diagnosis expressed in a particular lip area, but mainly by the size, shape, and direction that the major and minor grooves assume in a specific printing, leading to the uniqueness of the method. The presence of some secondary (non-predominant) grooves would make the lip prints of monozygotic twins a unique record, corroborating Tsuchihashi's reports (8). This same study also evaluated 5 families consisting of father, mother and two biological children, noting that with the exception of 2 children, all the others had a pattern similar to one of their parents' (father or mother). This fact may be attributed to hereditary influence on the lip patterns, corroborating the findings of the present study, where agreements of the predominant groove patterns were relevant for the groups of biological siblings of same father and mother, either twins or not. The intermediate pattern of agreements in G2, where values were between those obtained in the groups G1 and G3, also emphasizes the importance of hereditary determinants for cheiloscopic features, as reported in the literature.

Even considered as an old method, there are few publications on this topic (16), especially some linked to the particularities of a family sample, including twin pairs. Another limitation was related to the difficulty in selecting a particular sample that met the inclusion and exclusion criteria of this study, which required a convenience selection, although pairing by age and sex in the groups minimized the possibility of methodological biases.

In conclusion, both the lip thickness and commissures had high agreement rates among twin siblings (G1) and non-twin siblings of same parentage (G2) and their functionality to accept and/or decline a suspect record is possibly minimized when comparing biological siblings. In all analyzed sub-quadrants, there were higher agreement rates concerning the main groove pattern among $\mathrm{G} 1$ pairs, followed by $\mathrm{G} 2$ and $\mathrm{G} 3$ pairs. These findings indicate the influence of heredity on the formation of the groove pattern found on the lips.

\section{Resumo}

Este estudo teve como objetivo investigar o padrão queilocópico entre gêmeos monozigóticos, (GM), irmãos não gêmeos (NG) e os individuos sem herança genética em comum (SHG). A amostra foi composta por 20 pares de gêmeos monozigóticos (G1), 20 pares de irmãos não gêmeos (G2) e 20 pares de individuos sem grau de parentesco (G3). Foram avaliadas a espessura, as comissuras e os sulcos labiais, sendo os últimos classificados como: I - linhas verticais completas; I' - linhas verticais incompletas; II - linhas bifurcadas; III - linhas entrecruzadas; IV - linhas reticulares e $\mathrm{V}$ - padrão indeterminado, divididos em 8 regiões labiais (sub-quadrantes). Os dados foram analisados usando estatísticas descritiva e inferencial, com nivel de significância de 5,0\%. Para avaliar a concordância entre os pares G1, G2 e G3 foram utilizados o Coeficiente de Correlação de Concordância (CCC) e coeficiente Kappa, com intervalos com 95,0\% de confiança. Em relação à espessura labial, verificou-se fraca concordância $(<0,90)$ para o grupo total, sendo mais elevada entre os pares $\mathrm{G} 1$ (CCC de 0,25 a 0,83 e de 0,34 a 0,86, lábios superior e inferior, respectivamente), seguida de $\mathrm{G} 2$ (CCC de $-0,03$ a 0,70 e de $-0,21$ a 0,62, lábios superior e inferior, respectivamente) e G3 (CCC de $-0,25$ a 0,56 e de $-0,38$ a 0,34, lábios superior e inferior, respectivamente). Para a comissura labial, os valores de concordância Kappa foram 1,00 para G1, 0,45 para G2 e -0,24 para G3. No estudo do tipo sulcular principal por subquadrante, o Kappa variou de 0,48 a 0,87 para $\mathrm{G} 1,017$ a 0,59 para $\mathrm{G} 2$ e $-0,18$ a 0,19 para G3. Gêmeos monozigóticos apresentaram um relevante percentual de coincidências. Semelhanças também estiveram presentes entre os NG, enquanto que os individuos SHG apresentaram maiores divergências em comparação com os seus pares, indicando a influência das relações hereditárias sobre as características queiloscópicas herdadas.

\section{Acknowledgements}

The authors thank the Coordenação de Aperfeiçoamento de Pessoal de Nivel Superior (CAPES) and the Conselho Nacional de Desenvolvimento 
Científico e Tecnológico (CNPq) for supporting this study.

\section{References}

1. Herrera LM, Fernandes CMS, Serra MC. Human identification by means of conventional and digital cheiloscopy: a study of the literature. Rev Gaúcha Odontol 2013;61:113-120.

2. Mutalik VS, Menon A, Jayalakshmi N, Kamath A, Raghu AR. Utility of cheiloscopy, rugoscopy, and dactyloscopy of human identification in a defined cohort. J Forensic Dent Sci 2013;5:2-6.

3. Barros GB, Silva M, Galvão LCC. Queiloscopic study among dental students at the State University of Feira de Santana - BA. Rev Saúde Com 2006;1:3-11.

4. França GV. Legal Medicine. 10th ed. Rio de Janeiro: Guanabara Koogan, 2015.

5. Suzuki K, Tsuchihashi Y. Two criminal cases on lip print. J Forensic Sci 1975;5:171-172.

6. Russell LW, Welch AE. Analysis of lipsticks. Forensic Sci Int 1984;25:105116.

7. Koneru $A$, Surekha $R$, Nellithady G, Vanishree $M$, Ramesh D, Patil R. Comparison of lip prints in two different populations of India: Reflections based on a preliminary examination. J Forensic Dent Sci 2013;5:11-15.

8. Tsuchihashi Y. Studies on personal identification by means of lip prints. J Forensic Sci 1974;3:233-248.

9. Renaud M. L'identification cheiloscopique en Medicine Legal. Le Cirurgien Dentist de France 1973;2:65-69.

10. Suzuki K, Tsuchihashi Y. Studies on the lip print II. Shikwa Gakuho 1970;70:498-499.

11. Pereira MG. Epidemiology: theory and practice. 1th ed. Rio de Janeiro:
Guanabara Koogan; 2001.

12. Utsuno $H$, Kanoh $T$, Takodoro 0 , Inoue K. Preliminary study of post mortem identification using lip prints. Forensic Sci Int 2005;149:129132.

13. McBride G. A proposal for strength-of-agreement criteria for Lin's Concordance Correlation Coefficient. NIWA Client Report: HAM2005062; 2005.

14. Landis RJ, Koch GG. The measurement of observer agreement for categorical data. Biometrics 1977;33:159-174.

15. Shandu SV, Bansal H, Monga P, Bhandari R. Study of lip print pattern in a Punjabi population. J Forensic Dent Sci 2012;4:24-28.

16. Prahbu RV, Dinkar AD, Prahbu VD, Rao PK. Cheiloscopy: revisited. J Forensic Dent Sci 2012;4:47-52.

17. Barros GB. Cheiloscopy: use of the technique in the forensic identification. [Dissertation], University of São Paulo. 2006.

18. Muñoz MCN. Nuevas aportaciones al processado de huellas labiales: los lisocromos em queiloscopia. [Dissertation], Facultad de Medicina y Odontología de la Universitad de Valencia. 2004.

19. Venkatesh R, David MP. Cheiloscopy: an aid for personal identification. J Forensic Dent Sci 2011;3:67-70.

20. Domiaty MAE, Al-gadai SA, Elayat AA, Safwat MDE, Galal AS. Morphological patterns of lip prints in Saudi Arabia at Almadinah Almonawarah province. Forensic Sci Int 2010;200:179e.1-e.9.

21. Hirt L, Göttsche H, Goedde HW. Lip prints: variability and genetics. J Human Evol 1977;6:709-710. 